\title{
Analogue: On Zoe Leonard and Tacita Dean
}

\author{
Margaret Iversen
}

It is only now, with the rise of digitalization and the near-obsolescence of traditional technology, that we are becoming fully aware of the distinctive character of analogue photography. This owl-of-Minerva-like appreciation of the analogue has prompted photographic art practices that mine the medium for its specificity. Indeed, one could argue that analogue photography has only recently become a medium in the fullest sense of the term, for it is only when artists refuse to switch over to digital photographic technologies that the question of what constitutes analogue photography as a medium is selfconsciously posed. While the benefits of digitalization-in terms of accessibility, dissemination, speed, and efficiency-are universally acknowledged, some people are also beginning to reflect on what is being lost in this great technological revolution. In this context, artists' use of analogue film and the revival of early photographic techniques should be regarded as timely interventions, although these may strike some as anachronistic. This essay does not attempt an ontological inquiry into the essential nature of the analogue; rather, it is an effort to articulate something about the meaning of analogue photography as an artistic medium for contemporary artists by paying close attention to its meaning and stakes for particular artists. Instead of presenting a general survey, I want to consider the work of just two artists, Zoe Leonard and Tacita Dean, both of whose work is concerned with what is being lost. As Leonard put it: "New technology is usually pitched to us as an improvement.... But progress is always an exchange. We gain something, we give something else up. I'm interested in looking at some of what we are losing." Tellingly, both artists

1. Zoe Leonard, "Out of Time," October, no. 100 (Spring 2002): 89. 
have produced exhibitions simply called Analogue. Leonard gave the title to a large project she did between 1998 and 2009 consisting of 412 silver gelatin and c-prints of local shop fronts in lower Manhattan and poor market stalls around the world. ${ }^{2}$ Dean used it for a 2006 retrospective exhibition of her films, photographs, and drawings.

Debates about the difference between digital and analogue photographic art practices often turn on the issue of agency and automatism. ${ }^{3}$ This issue has become prominent because, for the past few decades, several celebrated artists have been producing large-scale photographic images in which artistic intention through digital manipulation is foregrounded. In the work of Jeff Wall or Andreas Gursky, for example, the process involves a kind of painting or collage with pixels where emphasis is placed on the carefully controlled synthesis and composition of multiple images to form the final picture. Both Leonard and Dean, however, are resistant to manipulation. Instead, their work values the analogue's openness to chance and the medium's indexicality. Of course, artists using analogue film exercise considerable agency selecting camera and film, in framing, focusing, and setting aperture size, time of exposure, and so on, as well as similar choices throughout the printing process. Yet, for the artists I consider, all these forms of intervention do not compromise the analogue's photochemical continuity with the world. The analogue is defined as a relatively continuous form of inscription involving physical contact. From this point of view, the photogram, produced by contact between an object and light sensitive paper, only makes explicit what is implicit in all analogue photography. Conversely, digital photography's translation of light into an arbitrary electronic code arguably interrupts that continuity. This dis-

2. There are actually three versions of Analogue: 412 photographs displayed as an installation, a book of 90 photographs, and a series of dye transfer prints that can be displayed in series or individually.

3. See, for example, William J. Mitchell, "Digital Images and the Postmodern Era," The Reconfigured Eye: Visual Truth in the Post-Photographic Era (Cambridge, Mass., 1992), pp. 8-10.

Margaret Iversen is professor in the School of Philosophy and Art History, University of Essex, England. Her most recent books are Beyond Pleasure: Freud, Lacan, Barthes (2007), Writing Art History (coauthored with Stephen Melville, 2010), and Chance (2010). Her other published books include Alois Riegl: Art History and Theory (1993) and Mary Kelly (1997). She coedited "Photography after Conceptual Art" for Art History (2009) and was director (with Diarmuid Costello) of the Arts and Humanities Research Council research project, "Aesthetics after Photography." 
continuity precedes the effects of digital editing or computerized image synthesis. ${ }^{4}$

These reflections on the distinction between analogue and digital inevitably raise the thorny question of whether digitalization has compromised the authority of the photographic document. Those who argue the case are likely to underestimate the extent to which the analogue document is naturally distorted and intentionally manipulated. ${ }^{5}$ They also tend to neglect the fact that digital photography provides journalists, astronomers, and doctors, among others, with accurate information about the objects or states of affairs that were the image's origin. Both technologies are causally bound up with their objects and susceptible to manipulation. From this practical point of view, there is no substantive difference between the two technologies. ${ }^{6}$ From an artistic point of view, however, I argue that there is an important difference. While the truth-value of photography is a much-debated and intriguing topic, it is not the focus of my interest in the analogue; my concerns are aesthetic rather than ontological or epistemological. My theme is the impact of the new technology on artistic practice. Digital photography has had inescapable consequences, not only for those artists who have adopted it, but also for those who have not. It is too early to say whether digital photography constitutes a new medium or if, like the introduction of color film, it is a modification of an old one. In any case, it is possible to point to important shifts in practice that have in fact occurred. The interface of photographic technology with the computer and the availability of large-scale digital printing have revolutionized photographic art in the last thirty years. In response, artists working with the analogue have tended to emphasize the virtues or specific character of predigital technologies. Since digital cameras are designed to mimic the functions of analogue ones, amateur photographers are probably unaware of much difference in the resulting image. Artists, however, are interested in investigating their materials and so are likely to seize on a technical difference and amplify it. An example of this trend can be seen in the work of artists using digital photography who enlarge low resolution pictures in order to make the pixel grid visible. Meanwhile, certain contemporary analogue photographers, such as Hiroshi Sugimoto, are reviving earlier printing

4. For a balanced discussion of these issues, see Phillip Rosen, Change Mummified: Cinema, Historicity, Theory (Minneapolis, 2001), esp. chap. 8, "Old and New."

5. On the disparity between prephotographic reality and the image, see, for instance, Joel Snyder, "Picturing Vision," Critical Inquiry 6 (Spring 1980): 499-526, and John Tagg, The Burden of Representation: Essays on Photographic Histories (Amherst, Mass., 1988), pp. 1-3.

6. See Snyder, "Photography, Chemical and Numerical," lecture, American Society of Aesthetics, 6 Nov. 2008. 
techniques to achieve effects like the incomparable velvety blacks and luminous whites of silver gelatin prints.

As we shall see, in response to digitalization, both Leonard and Dean have found ways of making the character of their medium salient. They adopt a receptive attitude and welcome chance effects. They try to make the material, tactile quality of the medium palpable. Both artists are drawn to objects that bear the indexical marks of weather, age, and use- discovering an elective affinity between these things and the way they imagine their medium. An analogue record of those traces doubles the indexicality of the image, making the image a trace of a trace and thereby drawing attention to an aspect of the medium within the image. For example, both Leonard and Dean have made series of photographs of misshapen trees. As in these series, their work often focuses on the damaged texture of the world, for it is precisely this texture that is compromised by the digitally "enhanced" environment characteristic of commercial digital photography. In short, they associate analogue photography with a kind of attentive exposure to things in the world marked by chance, age, and accident.

This idea of exposure, in both its photographic and ethical senses, informs my sense of the work of Leonard and Dean. A brilliant exposition of the poetics of exposure can be found in Eric Santner's On Creaturely Life: Rilke, Benjamin, Sebald.7 The book's point of departure is Rainer Maria Rilke's poetic evocation of the creaturely gaze in his eighth Duino Elegy. ${ }^{8}$ According to Rilke, this gaze is quite different from our ordinary sort of perception, which is reflective, conceptually mediated, articulated, and crossed by various purposes that tend to position the subject over against an object. Our consciousness is closed in on itself, reflecting ready-made representations. The human gaze is normally twisted by the knowledge of death and clouded by memory. For Rilke, animals, children, those in love, and those so near death that they can see beyond it are best placed to look, not at the fully constituted objects of habitual experience, but into the Open. ${ }^{9}$ This romantic conception of the creaturely was subsequently taken up and critiqued by Martin Heidegger and then modified by a German-

7. See Eric L. Santner, On Creaturely Life: Rilke, Benjamin, Sebald (Chicago, 2006).

8. See Rainer Maria Rilke, Duino Elegies, trans. C. F. MacIntyre (New York, 2007). The Elegies were written $1912-1922$.

9. Reading to the end of Rilke's poem, one discovers that this paradise is far from perfect:

And how perturbed is anything come from a womb when it has to fly! As if afraid of itself, it jerks through the air, as a crack goes through a cup. As the track of a bat tears through the porcelain of evening. [Ibid., p. 65] 
Jewish tradition including Franz Kafka, Walter Benjamin, and W. G. Sebald. For these writers, creaturely life designates the condition of humans in modernity, that is, the condition of thrownness into an enigmatic Open where one is exposed to political power and surrounded by the cryptic ruins of defunct forms of life. Fundamental moods of boredom and, for Benjamin melancholy, are attuned to this sort of traumatized creaturely exposure to the Open..$^{10}$ To this list should be added the surrealist's favored attitude of disponibilité, which involves openness to whatever befalls one, like the disconcerting chance encounter with the found object.

Santner's chapter on Sebald bears most closely on our topic. The degree to which photography, chance, and coincidence are important factors in Sebald's narratives is well known. For example, the key event in Austerlitz's life- his entering the ladies' waiting room in Liverpool Street Station a few weeks before it was demolished-is presented as a chance occurrence. That event precipitated the recovered memory of his childhood transportation from Nazi Germany and his prior life in Germany and so unlocked what had long been constraining his subsequent life. In this case, it was a lucky break, a happy chance, that opened up for him the possibility of change. History and memory were, so to speak, condensed in the architecture. Such objects, writes Sebald, "carry the experiences they have had with us inside them and are-in fact- the book of our history opened before us," if we are lucky enough or open enough to encounter them. ${ }^{11}$ Sebald's interest in this sort of contingency explains the inclusion of photographs in his books. To describe them as illustrations of the text would be to diminish their importance, for opaque, old, found photographs or clippings from newspapers were often the starting point for his literary investigations. He closely associated photographs with loss and chance recovery. In an interview, he remarked that old photographs are almost destined to be lost, vanishing in the attic or a box, "and if they do come to light they do so accidentally, you stumble upon them. The way in which these stray pictures cross your path, it has something at once totally coincidental and fateful about it." ${ }^{12}$ In addition, photography is allied with the circumstantial, the detail, the purely contingent, and it is this feature that most associates photography with the creaturely gaze. Benjamin's traumatic theory of photography and Roland Barthes's mad realism both involve a sort of

10. Giorgio Agamben has also taken an interest in the concept of the Open. See Giorgio Agamben, The Open: Man and Animal, trans. Kevin Attell (Stanford, Calif., 2004).

11. W. G. Sebald and Jan Peter Tripp, Unrecounted, trans. Michael Hamburger (London, 2004), pp. $78-79$.

12. Quoted in Santner, On Creaturely Life, 152. 
radical exposure to the creaturely condition of the other. ${ }^{13}$ This condition is figured in the opening pages of Sebald's Austerlitz. The narrator visits the Nocturama at the Antwerp Zoo, where he watches a raccoon with a serious expression on its face washing a piece of apple over and over again. The animal's large eyes remind the narrator of the gaze of certain painters and philosophers who seek to penetrate the darkness. ${ }^{14}$ In my account of the work of Leonard and Dean, I further develop the idea of exposure in its ethical and photographic senses. Their attitude to the world and to the medium is, I argue, best summed up by the term exposure. But, first, a brief detour is necessary through Thierry de Duve's phenomenological description of two different sorts of photographic practice.

In "Time Exposure and Snapshot: The Photograph as Paradox," de Duve describes two sorts of photography. Couched in terms of a technical difference, his typology offers a way of rethinking photography as a medium with two faces. For de Duve, time exposure photography emphasizes the light sensitivity and indexicality of a medium that is attuned to objects. The instantaneous snapshot, by contrast, tries to capture events. De Duve aims to expand his analysis of photography beyond a purely semiotic reading to include "the affective and phenomenological involvement of the unconscious with the external world, rather than its linguistic structure." Accordingly, he aligns the snapshot with trauma and the time exposure with mourning. He reasons that the snapshot isolates a single point in time and space and this prevents description or narration; one is rendered "momentarily aphasic" in a way that is analogous to the breakdown of symbolization characteristic of trauma. ${ }^{15}$ In addition, the temporality of the snapshot is always one of a missed encounter-too late to change what is about to happen but too early to see what transpires. The stillness and chiaroscuro of a time-exposure photograph, on the contrary, allow for an extended duration of viewing and reverie. As a substitutive object, moreover, it facilitates the work of mourning. One can, of course, cite counterexamples to de Duve's typology (the blurred long-exposure of a football

13. Benjamin describes early photographs as marked by the spark of contingency. See Walter Benjamin, "Little History of Photography," Walter Benjamin: Selected Writings, trans. Edmund Jephcott, et al., ed. Michael W. Jennings, Howard Eiland, and Gary Smith, 4 vols. (1931; Cambridge, 2005), 2:507-30. Roland Barthes proposes the emotion of pity to characterize his response to the photographs that touch him; see Roland Barthes, Camera Lucida: Reflections on Photography, trans. Richard Howard (New York, 1981), pp. 116-17. For Santner, exposure involves pity for the "creatureliness" of the other.

14. See Tacita Dean, "W. G. Sebald," October, no. 106 (Fall 2003): 122-36.

15. Thierry de Duve, "Time Exposure and Snapshot: The Photograph as Paradox," October, no. 5 (Summer 1978): 118; rpt. de Duve, "Time Exposure and Snapshot: The Photograph as Paradox," in Photography Theory, ed. James Elkins (New York, 2007), pp. 109-24. 
player in action; the portrait with hair and clothes dishevelled by a gust of wind), but the effect of these images lies precisely in their going against the grain of the type normally associated with the genre.

De Duve cites Barthes's early formulation in "Rhetoric of the Image" (1964) of the photographic image as both "here-now" and "there-then."16 Yet, when he uses Barthes to describe the snapshot's "here and the formerly" ${ }^{\prime 17}$ as traumatic, de Duve adds a new dimension that Barthes then seems to have adapted two years later in Camera Lucida. However, he did so in such a way that it came to characterize photography in general, and more particularly time-exposure portrait photography, examples of which form the bulk of Barthes's illustrations. Barthes's revision seems to me entirely justified, for an athlete caught in mid-jump, de Duve's prime example of the snapshot, has none of the pathos of an old portrait photograph. In any case, the isolation of the experience of an event, characteristic of the snapshot for de Duve, is not a feature of trauma. On the contrary, for Sigmund Freud and for Benjamin after him, it is rather the way that consciousness defends against trauma. ${ }^{18}$ The ballistic art of film with its jump cuts and montage effects is conceived by Benjamin as a means of adapting to modern life, of learning to screen potentially harmful impressions and so preventing them from entering experience. ${ }^{19}$ Charles Baudelaire, Benjamin's exemplary poet of the shock-experiences of crowds, technology, and gambling, compared the work of the poet or artist to a fencer parrying blows. Baudelaire's poetry, wrote Benjamin, "exposes the isolated experience in all its nakedness." ${ }^{20}$ In short, what de Duve refers to as trauma is rather consciousness as it screens and parries the shocks of contemporary life. ${ }^{21}$ Traumatic experience, conversely, is defined by Freud as having such an overwhelming or ungraspable character that it slips past those defenses to form a reserve of unconscious memory traces, psychical scars that can only be retrieved retrospectively and involuntarily. ${ }^{22}$ It is important for my

16. Barthes, "Rhetoric of the Image," trans. Stephen Heath, Image-Music-Text (New York, 1977), p. 44.

17. Misquoted in de Duve, "Time Exposure and Snapshot," p. 117.

18. Benjamin uses two German words where we have only the one word, experience. Erlebnis and Erfahrung are usually translated as "isolated or immediate experience" and "long experience," respectively.

19. See Benjamin, "Work of Art in the Age of Reproducibility (Third Version)," Walter Benjamin, 4: 251-83, esp. p. 267.

20. Benjamin, "On Some Motifs in Baudelaire," Walter Benjamin, 4: 336.

21. See ibid., p. 318, for Benjamin’s discussion of Chockerlebnis.

22. According to Freud, perception-consciousness and memory are two distinct systems, for, as he observed, "becoming conscious and leaving behind a memory-trace are processes incompatible with each other within one and the same system." He adds, in italics, "consciousness arises instead of a memory trace." While conscious experience quickly expires, 
argument to maintain this distinction between the shock effect of the snapshot and the traumatic effect of time-exposure photography. Time exposure is presented here as an alternative model of experience to the defensive, snapshot, parrying of the blows; it implies a receptivity or vulnerability or exposure to whatever is encountered.

What is fundamentally at issue here is an analogy between the subject of trauma who is marked by the sight of something that leaves an indelible trace on the psyche and the wide open camera lens and light sensitive medium that records on film a trace of whatever happens. André Breton conceived of the chance encounter in just these terms. The idea of objective chance governing the encounter with the found object is indebted to his reading of Freud's Beyond the Pleasure Principle. ${ }^{23}$ This is evident in one of Breton's key formulations: "Chance would be the form taken by external reality as it traces a path [se fraie un chemin] in the human unconscious." ${ }_{24}$ Bypassing the "protective shield against stimuli," traumatic events leave behind an indelible trace. ${ }^{25}$ The work of art as the paradigm case of a mind-formulated artifact wholly porous to the intentions of its maker is here challenged by an alternative practice that contrives ways to capture the unpredictability of our encounter with the world. Agency is involved in setting up the apparatus and in judging the outcome; between these moments, chance is allowed to intervene. While this bracketing of intentionality is a choice, the material that emerges is outside the artist's control. To put the case another way, the fact that an artist intentionally courts chance does not make everything that emerges from that process intentional, unless you claim that retrospective acceptance of a chance occurrence confers intentionality-but that does seem to me to stretch the concept to the breaking point.

\section{Zoe Leonard}

In her major series of photographs of shop fronts, Analogue, Leonard makes apparent the analogue character of her medium (fig. 1). For example, she leaves the black surround of the film with the brand names Kodak

memory traces are "often most powerful and most enduring when the incident that left them behind was one that never entered consciousness" (Sigmund Freud, Beyond the Pleasure Principle, in The Standard Edition of the Complete Psychological Works of Sigmund Freud, trans. James Strachey, 24 vols. [London, 1953-1971], 8: 25).

23. See Margaret Iversen, Beyond Pleasure: Freud, Lacan, Barthes (University Park, Penn., 2007), on the artistic and theoretical legacies of Freud's Beyond the Pleasure Principle.

24. André Breton, Mad Love, trans. Mary Ann Caws (London, 1987), p. 25.

25. Freud, Beyond the Pleasure Principle, 8:298. 


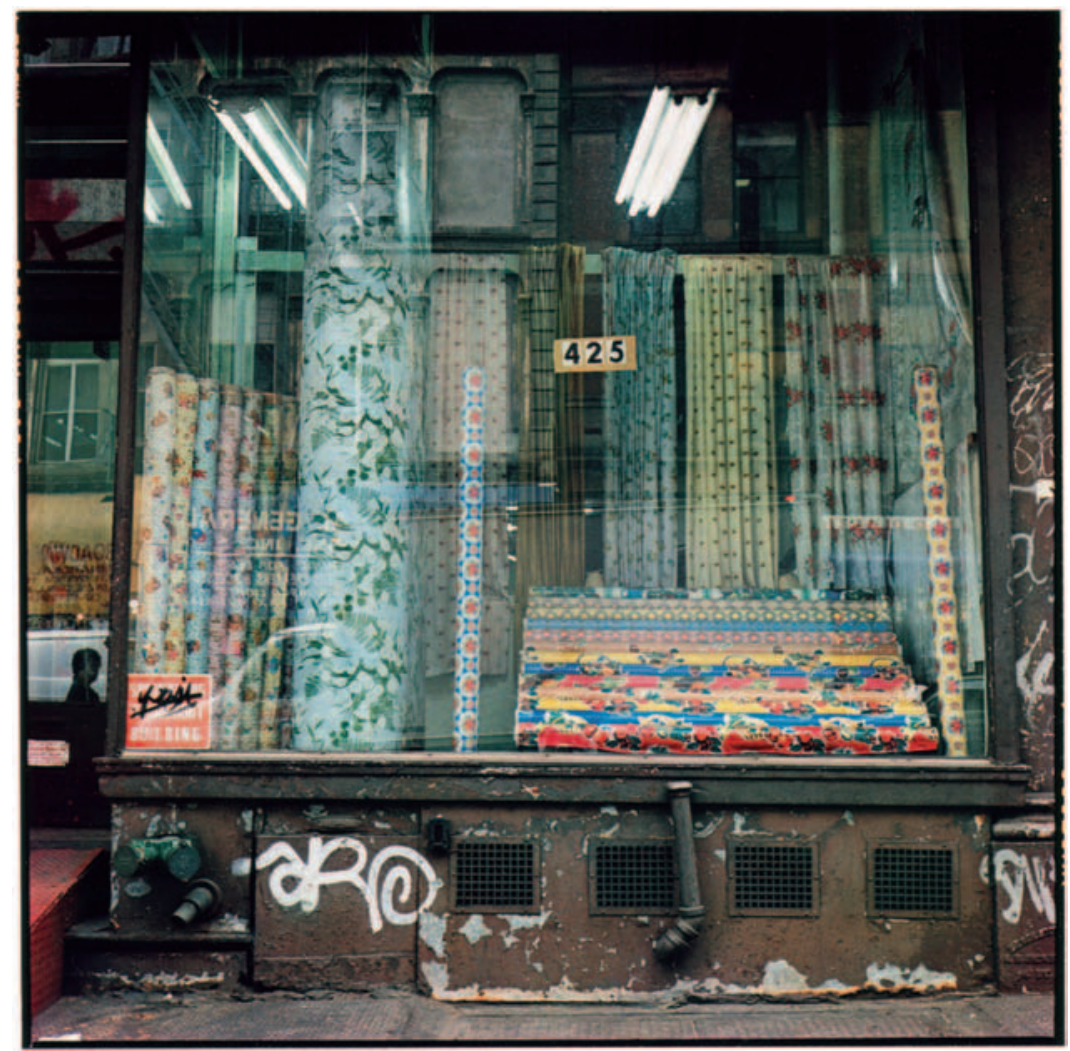

FIGURE 1. Zoe Leonard, Analogue, 1998 and 2007 (detail). (c) the artist, courtesy of Galerie Gisela Capitain, Cologne.

and Fuji clearly visible. She usually hangs them under glass with no frame or mat. The familiar square format of the prints, 11 in. $\mathrm{x} 11$ in., recalls pictures taken by classic analogue film cameras, like the old Rolleiflex she in fact used. They are also of modest size, although the full installation of all 412 prints, as was seen at Documenta XII in 2007, is monumental in scale. The impetus for the project, which involved a decade of work and thousands of pictures, was the gentrification of her neighborhoods in the Lower East Side of New York and in Brooklyn. The old linoleum store and local butcher were making way for new clothing boutiques and bars. Yet it was only at the point when "the layered, frayed and quirky beauty" of her neighborhood was on the point of disappearing that she realized how much she loved and depended on it. ${ }^{26}$ Although Analogue moves out from

26. Leonard, “Out of Time,” p. 89. 
Leonard's neighborhood, following the movement of unwanted clothes and multinational brand logos from New York to market stalls around the world, including Mexico City, Cuba, Kampala, Ramallah, and Eastern Europe, the photographer's relation to the things she documents always remains close-up, personal, and small scale.

Leonard's project, then, in some way resembles Eugène Atget's documentation of old Paris around 1900, which was also prompted by its ongoing demolition. There are clear allusions to Atget in her work: for example, in the fascination with shop windows, the attention paid to lowly and overlooked quarters, the avoidance of people, and in the organization of the photographs into thematic chapters. The Analogue book contains an essay by Leonard called "A Continuous Signal" (which is one definition of the word analogue) that is made up entirely of quotations from other writers and has a section devoted to Atget. There are also clear allusions to Walker Evans, who published a set of color photos of shop fronts in Fortune together with a statement about the wonders of shop front displays in New York: "What is as dependably entertaining as a really enthusiastic arrangement of plumbers' tools?" ${ }^{27}$ The examples of Atget and Evans seem to have offered Leonard a way of reconciling the document and art by using the photograph to frame the strange beauty of the ordinary and overlooked.

Shop fronts are Leonard's version of the surrealists' flea market where, in a receptive frame of mind, one might chance upon something personally revelatory. Leonard's photographs of found arrangements of objects and the story they tell are both personal and political. Her photographs are like formally uniform boxes that store the large found objects she encounters in her walks through the streets. The camera becomes a receptacle and the author a receiver. Kaja Silverman's "The Author as Receiver" discusses the fundamentally receptive character of photography and film, as well as the ethics of this position..$^{28}$ Other contemporary artists have also commented on the significance of vessels and containers in their work as signaling a receptive attitude. For example, commenting on a readymade piece, Gabriel Orozco remarked, "the shoe box is an empty space that holds things. I am interested in the idea of making myself — as an artist and an individual—above all a receptacle." He sums up by saying that "the ideas of the void, of the container and of vulnerability have been important in all my work. I also work a lot with the

27. Walker Evans, "The Pitch Direct," Fortune 58 (Oct. 1958): 139.

28. See Kaja Silverman, "The Author as Receiver," October, no. 96 (Spring 2001): 17-34. George Baker pursues a similar line of argument in a piece about Leonard, Dean, and Sharon Lockhart; see George Baker, "Loss and Longing," in 50 Moons of Saturn: T2 Torino Trienniale, ed. Daniel Birnbaum (Milan, 2008), p. 64. 


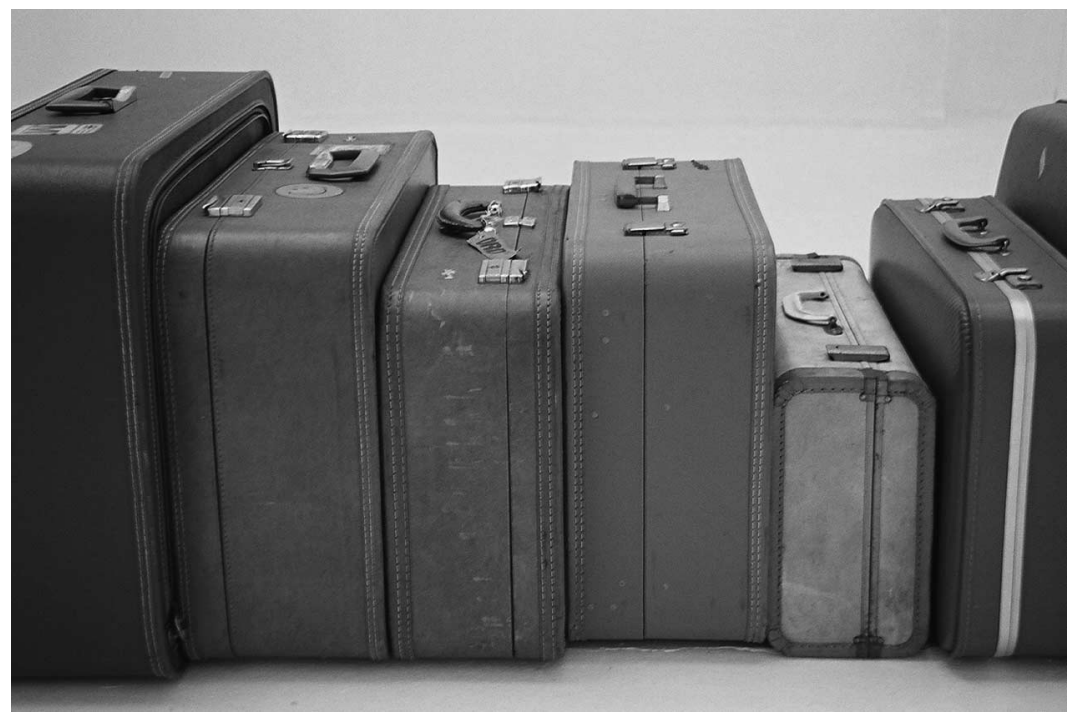

FIGURE 2. Zoe Leonard, 1961, 2003. (C) the artist, courtesy of Galerie Gisela Capitain, Cologne.

accident." Orozco makes the link, crucial for my argument, between receptivity and chance. ${ }^{29}$

Leonard's sensibility is both informed by and in tension with the formal rigor of minimalism. This ambivalent relation is made very apparent in an installation from 2003. The work, 1961, consists of forty-one different secondhand suitcases in subtle gradations of blue, arranged in a row spanning the length of the room (fig. 2). Leonard has referred to the work as autobiographical; the title is her birth year and the number of suitcases her age at the time of making. Personal identity is here turned into a series of spatial compartments, repositories of emotions, thoughts, and memories. There is an analogy at work, then, between the suitcases and her photography as both relate to what she has called "the impossible task of remembering." 30 The repeated modules recall Donald Judd's installations, but the status of the suitcases as found objects attracts a host of associationspeople in transit, migration, leaving home, anxiety, and so on. As Leonard has observed: "We use things to communicate complex ideas, feelings; it is

29. Gabriel Orozco, "Gabriel Orozco in Conversation with Guillermo Santamarina, Mexico City, August 2004," Gabriel Orozco (Madrid, 2005), p. 143. For more on the topic of chance and contemporary art see Chance, ed. Iversen (Cambridge, Mass., 2010).

30. Leonard, email to author, 26 May 2010. 
a dense, compact, potent language, the language of the found object." ${ }_{31}$ And, of course, they are receptacles_ closed and private. For Leonard, they evoke the idea of life as a journey: "A trip feels like a metaphor for life. It has a beginning, a middle and an end; it is a combination of choice and chance, of intention and surprise." ${ }^{32}$ For Leonard and, as we shall see, for Dean, the journey represents a paradoxical intention to abandon oneself to chance, to launch oneself into the unknown.

Although Leonard takes great care with the choice of materials and the framing and printing process, I think it is fair to say that, for her, photography is mainly an art of noticing, recording, and editing. In an interview, she once remarked, "I think my work is less about creating and more about observing." ${ }_{33}$ This restriction of authorial agency allows her to be open to the element of chance. One particularly good example of this strategy can be seen in the series tree + bag (2000), which simply records the random arrangements of plastic bags caught up in the branches of bare trees (fig. 3 ). Leonard made another series of trees she came across in her neighborhood that were struggling in the urban environment and surviving, albeit in a misshapen form, Tree and Fence (1998-99) (fig. 4). She commented: "I was amazed by the way these trees grew in spite of their enclosures-bursting out of them or absorbing them. The pictures in the tree series synthesize my thoughts about struggle. People can't help but anthropomorphize. I immediately identify with the tree." ${ }^{34}$ I find them to be quite painful images that speak of the deforming effects of power, confinement, and discrimination. Certainly a sense of vulnerability is powerfully conveyed by the way the bark of the trees is impressed by the rigid form of iron bars or a chain link fence. Yet Leonard is insistent that the living flesh of the trees should also be seen as resisting and overcoming those effects. The trees, she says, are "growing through and around these fences, so there is evidence of them as living, growing, adapting organisms." ${ }^{35}$ For her they are found, everyday emblems of the struggle for survival in inhospitable conditions.

Strange Fruit (for David) (1993-98) is a remarkable installation piece that consists of around three hundred skins of various fruits, each one emptied and carefully stitched together. They are scattered on the floor of the gallery, as if fallen from trees (fig. 5). The piece is a work of mourning

31. Leonard, "Salvage," unpublished manuscript.

32. Leonard, "Recollection," unpublished manuscript.

33. Leonard, "An Interview with Zoe Leonard," interview by Beth Dungan, Discourse 24 (Spring 2002): 80 .

34. Leonard, "A Thousand Words: Zoe Leonard Talks about Her Recent Work," Artforum 37 (Jan. 1999): 101; hereafter abbreviated "T."

35. Leonard, email to author, 26 May 2010. 
for all of Leonard's friends who had died from AIDS at a time before drugs were available. The act of stitching together the empty skins suggests that this vain effort might be reparation or restoration. It shows "a desire to make whole, to hold onto the form of something or someone" even after they are gone ("T," p. 101). And, for her, this desire to preserve is bound up with art making, with photography. While this desire is acknowledged, so also is the impossibility of keeping anything in perpetuity. "This work takes the material of the still life and reworks it. It borrows from the language of vanitas pictures and suggests that the artwork cannot preserve the person or the memory any more than the artwork can be preserved" ("T," p. 101). The skins, although owned by a museum, are slowly turning to dust. This piece, more than any other, brings to the fore the theme of the pain of separation. But I think it can act as a lens through which to view her work as driven not by nostalgia but by separation, loss, and desire. What becomes very clear with this work is how deeply the AIDS epidemic affected Leonard. It decimated the community around her, and the lack of public mourning for its victims made it harder to bear. The deserted streets of New York in Analogue refer to this traumatic emptying out, as well as to the closure of familiar neighborhood shops..$^{36}$

I have discussed two sculptural installations in my account of Leonard because I think that her understanding of photography, with its emphasis on the object represented, is close to sculpture. ${ }^{37}$ We recall that de Duve associated slow optics with the picture, which frames a lost or absent object, and contrasted it with the snapshot, which tries to capture an event. The paradigm of the first sort is the funerary portrait, that of the second, the abrupt and aggressive press photo. What this implies is that the modality of slow optics is spatial rather than temporal and tied to the object rather than the event. In other words, time exposure is more attuned to sculpture than the prefilmic snapshot. This was also Benjamin's view; describing a photographic portrait of Friedrich Schelling, he ascribed to the lengthy exposure time the emergence of the very tactile creases in the philosopher's face and in the folds of his coat. Schelling has grown into his coat and his face in the same way that his image has slowly grown into the light sensitive plate. Equally, "during the considerable period of the exposure, the subject (as it were) grew into the picture, in the strongest contrast

36. See Leonard, email to author, 10 Mar. 2011.

37. Leonard comments on why she works in both media: "In both cases, I work with found objects and found images, things I notice” (Leonard, “An Interview with Zoe Leonard,” p. 79). 


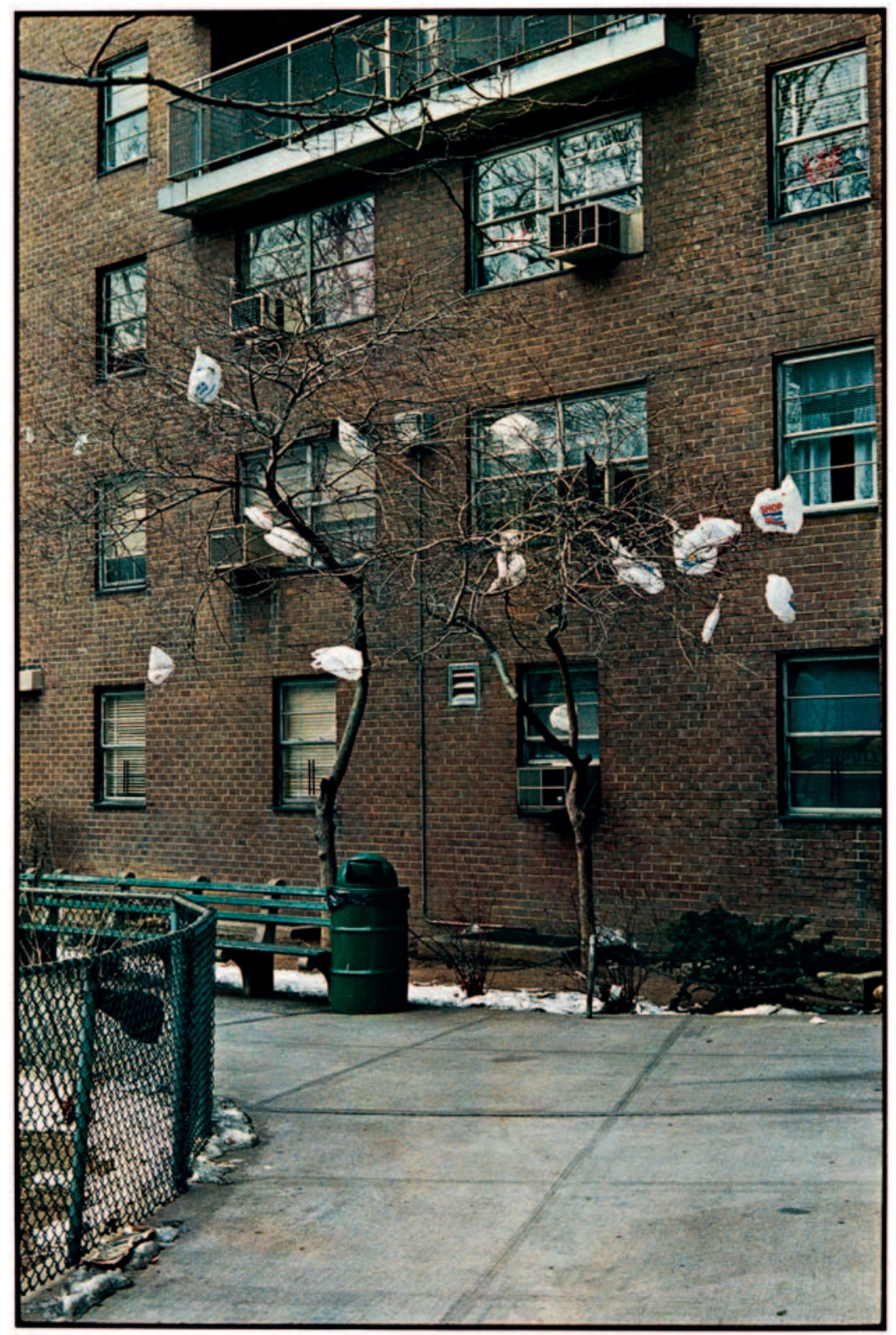

FIGURE 3. Zoe Leonard, Untitled (tree + bags), 2000 (detail). ( ) the artist, courtesy of Galerie Gisela Capitain, Cologne. 


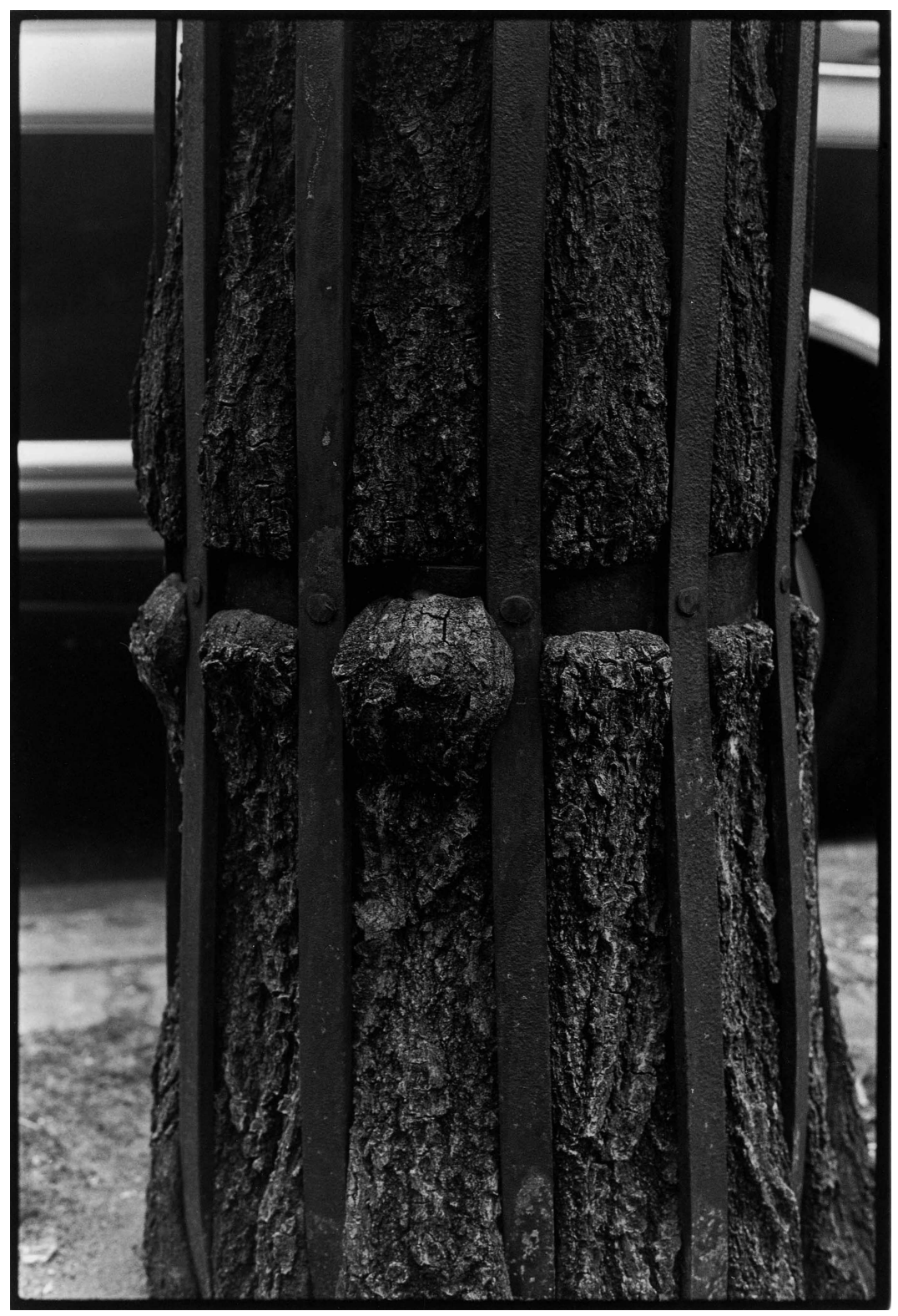

FIGURE 4. Zoe Leonard, (tree + fence), 1998-99 (detail). ( $)$ the artist, courtesy of Galerie Gisela Capitain, Cologne. 


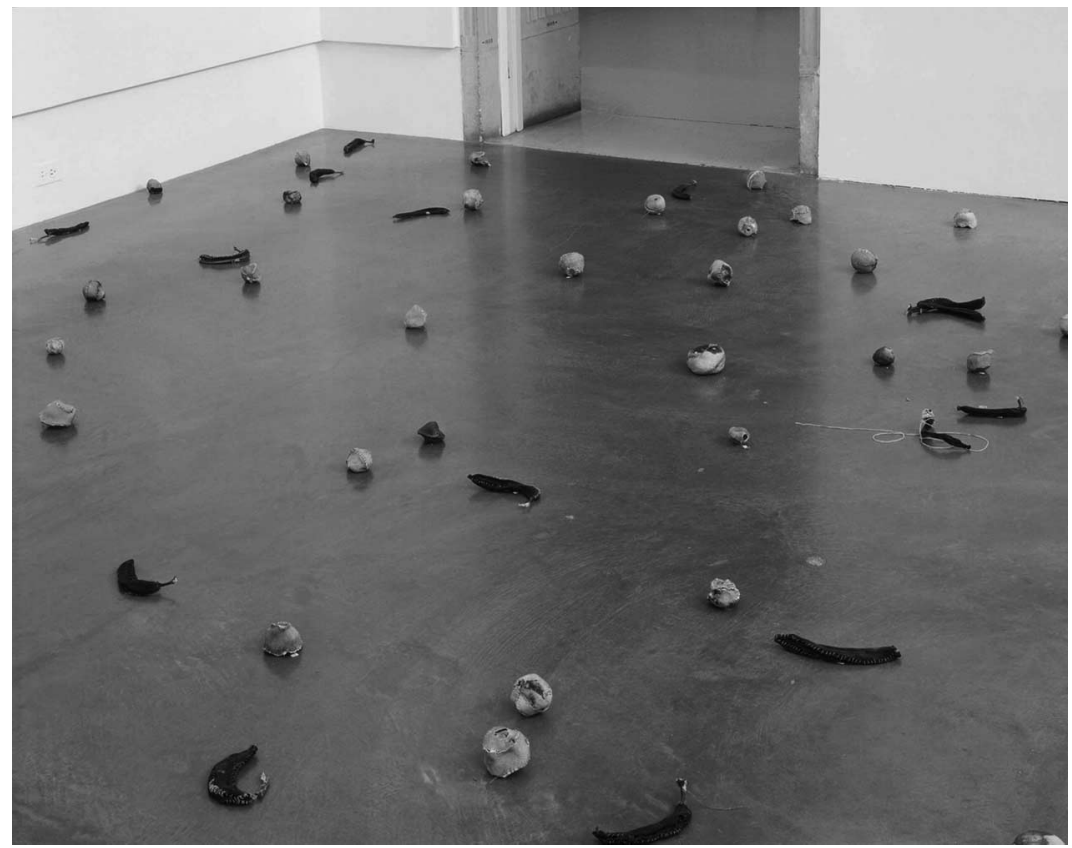

FIG URE 5. Zoe Leonard, Strange Fruit (for David), 1992-97 (installation view, Philadelphia Museum of Art). (C) the artist, courtesy of Galerie Gisela Capitain, Cologne.

with the appearances in a snapshot." This allowed him "to focus his life in the moment rather than hurrying on past it." ${ }^{8}$ Yet if this sort of photography is allied to sculpture, it is the sort of sculpture that is lined with absence, like Leonard's hollowed-out fruit skins or suitcases.

\section{Tacita Dean}

I hope that the constellation of linked concepts-including loss, trauma, the chance encounter with the found object, and what I am calling the time exposure style of analogue photography-is beginning to emerge. Without wishing to diminish the distinctive achievements of the two artists under consideration here, I now want to turn to the work of Dean and see if this same constellation might prove helpful in thinking about her work. I detect a similar sensibility at work; for example, her film Pie (2003) is a pastoral version of Leonard's tree + bag series. Shot out of the back window of her house in Berlin, the film shows a tree and the random comings and goings of magpies (fig. 6).

38. Benjamin, "Little History of Photography," 2:514. 


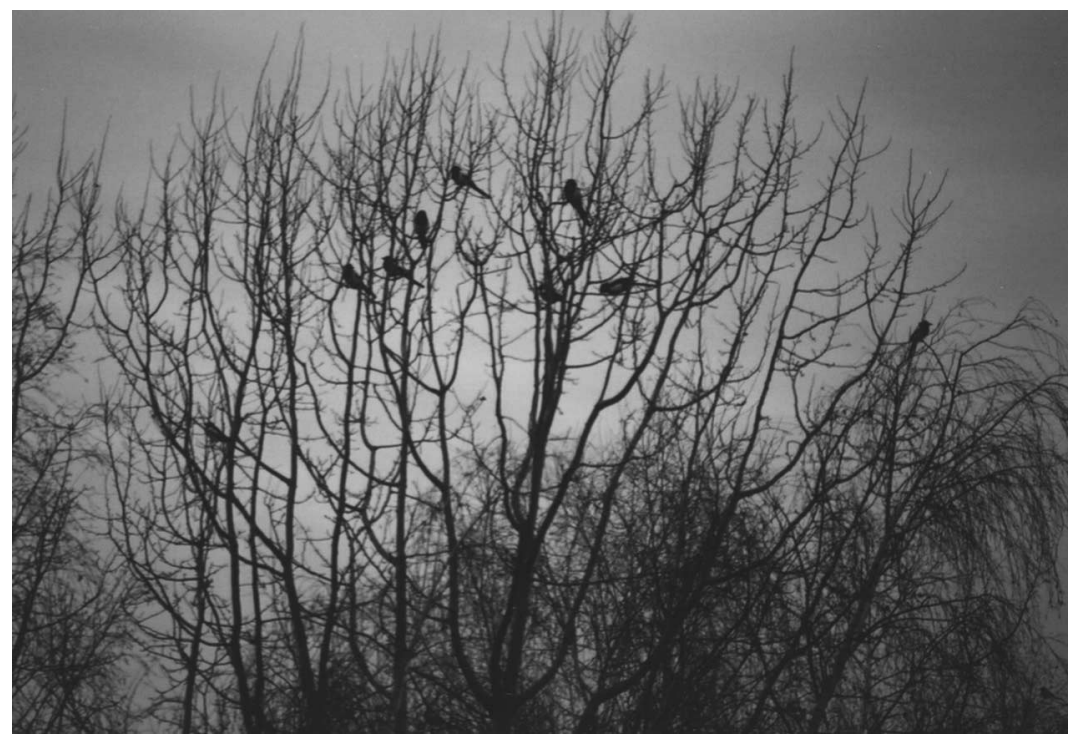

FI U URE 6. Tacita Dean, Pie, 2003, 16mm color film with optical sound, 7 mins. $\odot$ courtesy of the artist, Frith Street Gallery, London and Marion Goodman Gallery, New York and Paris.

Dean is even more outspoken than Leonard in her stand against the digitalization of everything. In the introduction to the catalogue for the exhibition, Analogue, she declares that analogue is a description "of everything I hold dear." She points out that analogue refers to a vast range of things, from the movement of hands on a watch to writing and drawing. She continues, "analogue implies a continuous signal—a continuum and a line, whereas digital constitutes what is broken up, or rather, broken down, into millions of numbers." While the convenience of digital media is wonderful, she confesses: "for me, it just does not have the means to create poetry; it neither breathes nor wobbles, but tidies up our society, correcting it and then leaves no trace." It is not "born of the physical world." We are being "frogmarched," she declares, into a digital future "without a backward turn, without a sigh or a nod to what we are losing." ${ }^{39}$ I can't help hearing in this last phrase an echo of the tragic myth of Orpheus, who descends into the underworld to rescue his dead wife, but, leading her back to safety, he anxiously turns around and in so doing loses her again. Dean's posture as an artist is just this turning around out of fear and love. As a sort of elegy for analogue film, Dean made a film of a French Kodak factory in operation shortly before it was to cease producing celluloid film

39. Tacita Dean, “Analogue,” Analogue: Drawings 1991-2006, ed. Theodora Vischer and Isabel Friedli (Göttingen, 2006), p. 8. 
stock (Kodak, 2006). I will confine my attention to those moments in her work when her conjoined interest in chance and analogue film is most apparent. In an email correspondence with me she confirmed her sense of the link between chance and the analogue: "a decline in one will invariably mean a decline in the other and our lives would be greatly impoverished for it." ${ }^{40}$ For all the excellent secondary literature on her work, this connection has not been adequately addressed.

Although she is mainly a filmmaker, Dean does use still photographyoften in the form of found photographs. She is an habitué of the flea market, a collector of the discarded with an eye for old postcards and family snaps_-"a junk junkie," she jokes. This sort of collecting is a matter of chance and luck - and Dean loves to court chance. She explicitly connects her collecting activity with the surrealist chance encounter: "I concur with André Breton when he spoke of the objective chance process being about external circumstances acting in response to unspoken desires and demands of the human psyche. I want to be in a position to allow the unforeseeable to happen." ${ }^{41}$ She started collecting old photographs in the mid-1990s, but this activity was given a focus only when she was commissioned to make a book for the art press Steidl. The result, Floh (2001), has been commented on at length by Mark Godfrey in "Photography Found and Lost: On Tacita Dean's Floh." 42 All 163 amateur photographs included in the book were found in various flea markets around the world and reproduced without comment (fig. 7). She has stated that this wordlessness is intentional: "I want them to keep the silence of the flea market; the silence they had when I found them; the silence of the lost object." ${ }^{43}$ Another prominent feature of the photographs in Floh is the plethora of mistakes. The quasi-accidental nature of photography can be seen, perhaps especially, in the hands of amateurs and even more so in those prints that end up in flea market bins. The photos are a regular inventory of technical errors: odd framing, poor focus, over- and underexposure, camera shake, and blurred subjects in motion, to name but a few. In some cases, one is inclined to surmise that the shutter must have been released accidently. The photographs themselves have also been subject to accidents and wear and tear such as fingerprints, scratches, and other marks. It is as though the condition of the medium were being explored by illustrating everything that can go wrong. The realization gradually dawns on one that these

40. Dean, email to author, 22 Sept. 2010.

41. Dean, An Aside: Selected by Tacita Dean (London, 2005), p. 4.

42. See Mark Godfrey, "Photography Found and Lost: On Tacita Dean's Floh" October, no. 114 (Autumn 2005): 90-119.

43. Dean, "Floh," Tacita Dean: Selected Writings 1992-2011, in Seven Books, 7 vols. (Göttingen, 2011), 6:50. 


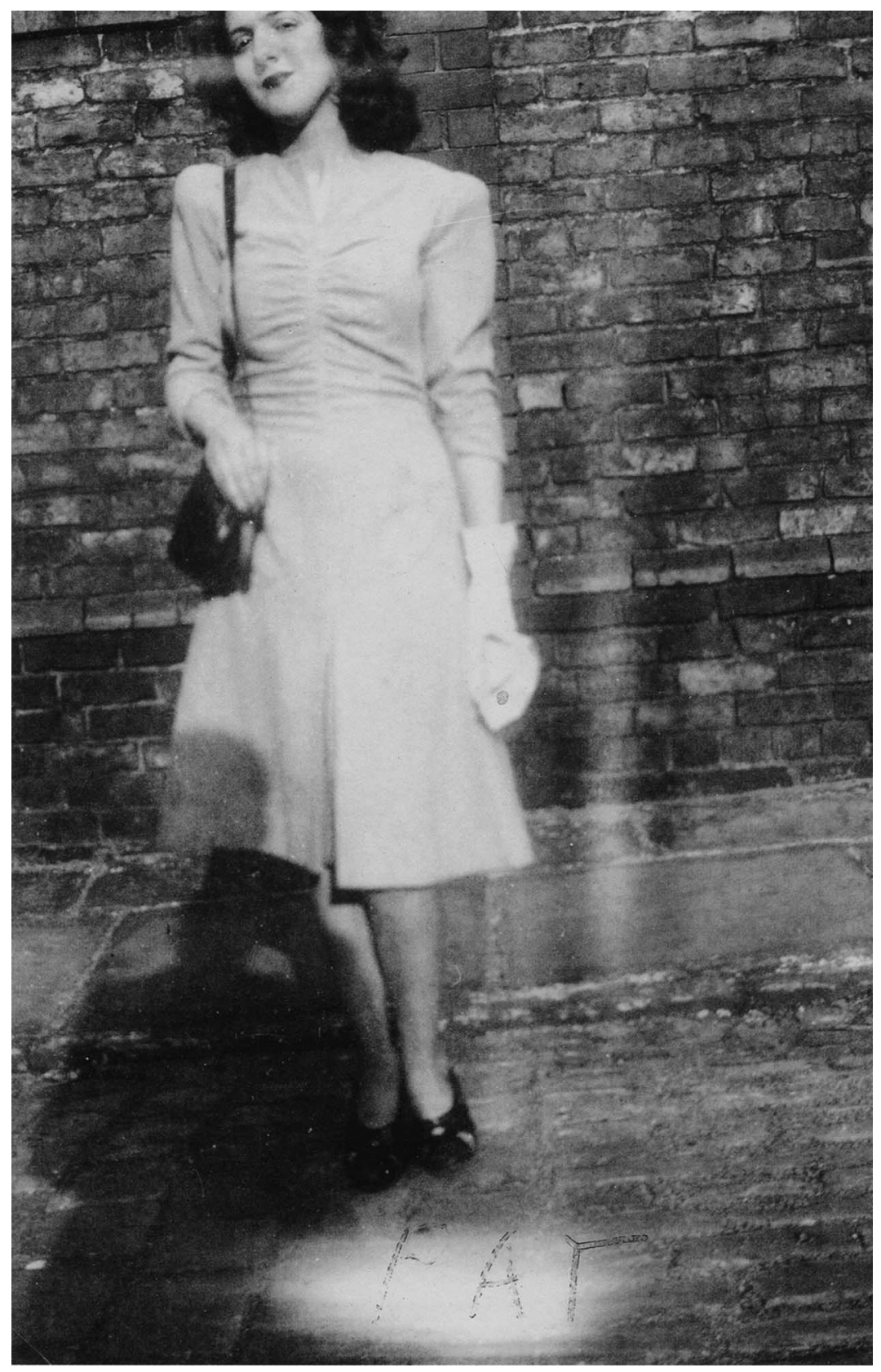

FIGURE 7. Tacita Dean, image from Floh, Steidl Books, 2001. @ courtesy of the artist, Frith Street Gallery, London and Marion Goodman Gallery, New York and Paris. 
sorts of accidents don't occur anymore because modern digital cameras take the guesswork out of taking pictures, and bad ones are instantly deleted. Furthermore, many people view their photographs on computers, so they never have a physical, paper form that could eventually wind up in a flea market. This change reflects the tidying-up of our world that Dean finds so impoverishing. The book thus preserves a hundred-year history of a certain kind of photography that was wide open to chance. Some of the results are enigmatic, others hilariously funny, and some incomparably beautiful.

The title Floh refers to the German for "flea," as in flea market, but it also refers to the flow of photographs detached from their moorings, cast adrift on a sea of discarded things. This sort of flow connects with the recurrent theme of the sea in Dean's work- a theme that has long been linked with Fortuna, goddess of luck or chance, who is often represented holding a billowing sail. Dean's large chalk drawings on blackboards of storm-tossed ships is a good example of how she uses her medium analogically in order to evoke the subject, for the chalk makes possible a process of erasure and redrawing that, like the sea, cannot be fixed. As she remarked: "Because of the flux, the drawing and the erasure, the whole process is so like the nature and the movement of the sea." 44 In a brief prose piece, "And He Fell into the Sea," Dean paid homage to a work by another artist in this traditionBas Jan Ader's final and unfinished performance, In Search of the Miraculous II (1975).45 Dean has written about Ader's and Donald Crowhurst's unsuccessful one-man sea voyages, both of which ended in death, which is, sadly, one possible consequence of giving oneself up to contingency, but not the only one. Michael Newman's contribution to Dean's collection of writings, Seven Books, bears closely on this issue. In his essay, "Salvage," he discusses Dean's use of the journey as a topos traditionally understood as a metaphor for human life. He notes that Dean added a subtitle to her film Disappearance at Sea II (1997)—Voyage de guérison (voyage of healing). ${ }^{46}$ In a short prose piece accompanying the film, Dean wrote of the myth of Tristan who, poisoned and beyond help, "surrendered himself up to the forces of the sea" and departed on a "journey of healing — where he floated alone on a small boat with no oars nor sail nor rudder," hoping to drift to some magical island where he would be cured. Floating alone in the boat for seven days and seven nights, wounded and weary, he finally finds the healing of Isolde. ${ }^{47}$ Dean adumbrates here the connections to be found

44. Tacita Dean Tacita Dean (Barcelona, 2001), p. 97.

45. See Dean, "Bas Jan Ader: And He Fell into the Sea," Tacita Dean: Selected Writings, pp. 91-92.

46. See Michael Newman, "Salvage," in Tacita Dean, 7 vols. (Paris, 2003), 7:[21]-[31] .

47. Dean, "Disappearance at Sea II," Tacita Dean: Selected Writings, p. 21. 


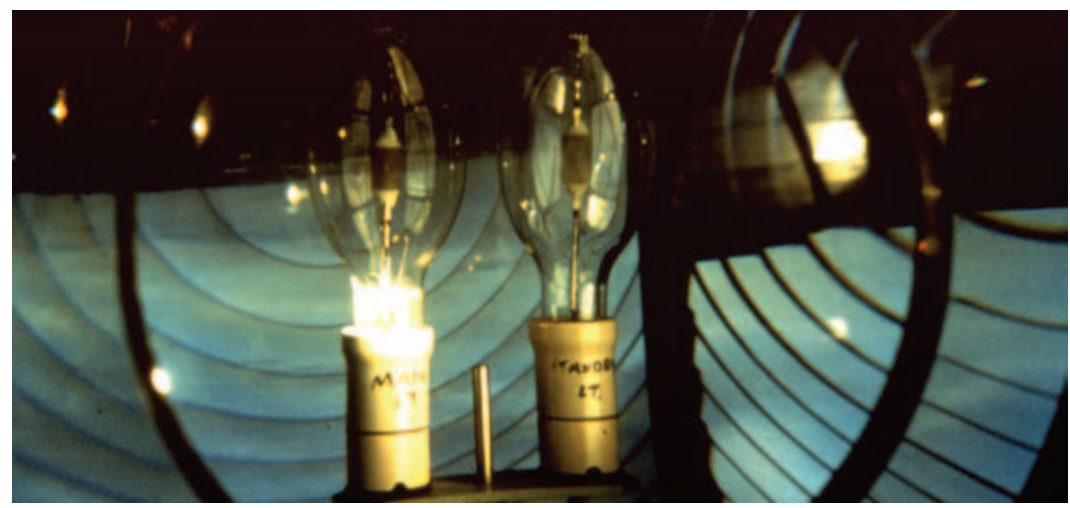

FI GURE 8. Tacita Dean, Disappearance at Sea II, 1996, 16mm color anamorphic film with optical sound, 14 mins. $\odot$ courtesy of the artist, Frith Street Gallery, London and Marion Goodman Gallery, New York and Paris.

amongst the sea, the journey of life, and the idea of confiding oneself to chance or giving oneself over to contingency as a way of opening up new possibilities in both life and art.

The strong thematic link in Dean's work between the sea voyage and chance is clear, but the question that concerns me is how this bears on her use of photography as a medium. Part of Disappearance at Sea II shows the beam of light from a lighthouse panning across the dark sea (fig. 8). This shot creates an effect similar to a film technique called the blind pan, a term that refers to a sweep across the field of vision without focal point or object. Although it is not about the sea, her film Fernsehturm (2001) is similar in

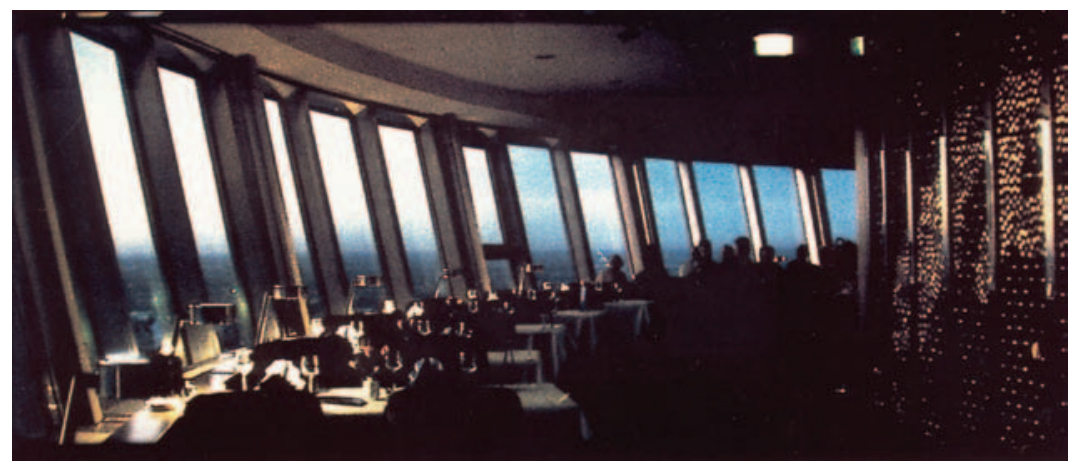

FIGURE 9. Tacita Dean, Fernsehturm, 2001, 16mm color anamorphic film with optical sound, 44 mins. (C) courtesy of the artist, Frith Street Gallery, London and Marion Goodman Gallery, New York and Paris. 
this respect (fig. 9). The film is a forty-four minute view of the interior of the revolving restaurant at the top of the television tower in former East Berlin. The movement is similar to a very slow 360-degree pan with a film camera, except in this case the camera is fixed while the restaurant slowly turns, bringing diners into view, during which time the earth itself turns and night falls. Dean was surprised to find how much it looked like the prow of a ship moving through the sea..$^{4}$ Interestingly, Dean made a series of photogravures called Blind Pan (2004) that show what appears to be high, blasted moorland spread sequentially over five large frames across which are inscribed stage directions for the self-blinded and lame Oedipus and his daughter Antigone making their way through the wilderness into exile. ${ }^{49}$ Haltingly moving forward, blind, with no definite aim, open to what happens, they are at sea on dry land. Dean attaches an ethical value to the blind pan, which, along with the long take with a fixed camera, is the cinematic version of what I've been referring to as time-exposure photography. Commenting on her free-associative curatorial project for Camden Arts Centre, An Aside, Dean made a pertinent comment that clearly has wider implications: "Nothing can be more frightening than not knowing where you are going, but nothing can be more satisfying than finding you've arrived somewhere without any clear idea of the route. ... I have at least been faithful to the blindness with which I set out." ${ }_{50}$

The blind pan in this context is a metaphor; Dean actually does not generally use pans or zooms. As she remarked in an interview: "I like the static shot that allows for things to happen in the frame. ... It is just allowing the space and time for whatever to happen, and that comes very much from the nature of film.... I tend to hold the frame until my film runs out." ${ }_{51}$ The facts that Dean's films border on still photography and that her favored format is widescreen are also relevant. The viewer, close to the wide screen in a gallery space, is free to pan across the image. In this context she remarks, "I have always thought that art works best when it is open to this subjectivity, when it is not bound by too much direction and

48. See Dean, “A Conversation with Tacita Dean," interview by Roland Groenenboom, in Tacita Dean (Barcelona, 2001), p. 104. I have not mentioned the sound tracks of Dean's films. They are analogue, optical sound recordings of ambient, found sound edited in the studio.

"Digital silence," she complains, "has a deadness," unlike "the prickled sound of mute magnetic tape” (Dean, “Artist Questionnaire: 21 Responses," October, no. 100 [Spring 2002]: 26).

49. For an interesting discussion of this piece, see Marina Warner, "Tacita Dean: Light Drawing In," in Gehen (Basel, 2006), p. 17.

50. Dean, An Aside, p. 4.

51. Dean, “A Conversation with Tacita Dean,” p. 91. 
intent." ${ }_{52}$ The work itself must be consigned to the contingencies of its reception.

Analogue photography and film as media of contemporary art after digitalization have become associated with a longer tradition of photography and writing on photography in which the camera eye is imagined as staring unguarded into an enigmatic Open. Within this tradition, openness, together with the automatism of the camera and the indexicality of analogue film, result in a kind of photography that is marked by contingency and seared by reality. As Dean so succinctly put it, analogue photography is "the imprint of light on emulsion, the alchemy of circumstance and chemistry" - a conception of the medium that I have elaborated in terms of the idea of exposure..$^{33}$

52. Dean, "In Conversation with Tacita Dean," interview by Marina Warner, in JeanChristophe Royoux, Warner, and Germaine Greer, Tacita Dean (London, 2006), p. 44.

53. Dean, “Analogue," p. 8. The reflections on analogue film contained in the catalog for Dean's Tate Modern Turbine Hall Unilever Commission Film are pertinent but arrived too late for consideration here; see Dean, Tacita Dean: Film, ed. Nicholas Cullinan (exhibition catalog, Tate Modern, 2011). 